\title{
Effects of Different Heel Heights on Heel Pressure Distribution for Calcaneal Spur Patients During Standing: Finite Element Analysis
}

\author{
Dwi Basuki Wibowo ${ }^{1, *}$, Achmad Widodo ${ }^{1}$, Gunawan Dwi Haryadi ${ }^{2}$, Agus Suprihanto ${ }^{3}$ \\ ${ }^{1}$ Center for Biomechanics, Central Laboratory of Research and Services, Diponegoro University \\ ${ }^{2}$ Center for Biomechatronics, Central Laboratory of Research and Services, Diponegoro University \\ ${ }^{3}$ Center for Biomaterials, Central Laboratory of Research and Services, Diponegoro University
}

\begin{abstract}
This study was performed to investigate heel height shoe for every patient which peak pressure in the heel area is lower than pain minimum compressive pressure. Heel heights of the shoes are standardized as $0-4 \mathrm{~cm}$. Sixteen patients with symptomatic heel spur participated in this study. Peak pressure due to its own weight is estimated using FEM and compared with the results of measurement using FSR (force sensing resistor). As heel height increased, peak pressure in heel region in the heel height $2 \mathrm{~cm}, 3 \mathrm{~cm}$ and $4 \mathrm{~cm}$ are larger $3.86 \%$ and smaller $5.04 \%$ and $22.11 \%$ respectively compared to the smallest pain compressive pressure. These peak pressures are significantly higher than the average pressure in $\mathrm{CH}$ (center of heel) measurement results due to the difference in the location of peak pressure to $\mathrm{CH}$ at average of $8.64 \pm 1.44 \mathrm{~mm}$.
\end{abstract}

\section{Introduction}

The pain in patients with calcaneus spur when standing or walking due to the pressure distribution on the calcaneus region large enough. During standing the calcaneal region support about $60 \%$ of body weight (BW) [1]. During walking there are peak loads for the Achilles tendon of $3.9 \mathrm{BW}$, the plantar fascia and the plantar ligaments of $1.8 \mathrm{BW}$, and the total contact force across the talocalcaneal joint and calcaneocuboid joint of $5.4 \mathrm{BW}$ and 4.2 BW respectively which all contribute to the loads on the calcaneus [2].

To reduce pressure using orthotic shoe can be done by raising heel height shoe [3-5]. Theresa Albon used 10 FSR (Force Sensing Resistor) sensors placed on various parts of the sole of the foot proved that as heel height increases more of the force is placed on the midfoot or arch of the foot while standing [6].

Many researchers have been used FEM (finite element method) as an experimental approach to predicting the pressure distribution between the foot and different shoe insole, which offer additional information such as the maximum pressure and its location in heel region [7-8]. To developed 3D model of foot, they used MR (Magnetic Resonance) image or CT (Computed Tomography) and MIMICS software to obtain skin surface and the boundaries. The SolidWorks software was commonly used to process the boundary 
surfaces and the ABAQUS or Ansys software was used to meshing grid of FE model and assembly the interaction between foot and insole.

This research is a new thing that is comparing the heel pressure between measurement result and FE model when using different heel heights shoe and comparing both results with the measurement of pain pressure around the spur growth using algometer. The method to model 3D solid of a plantar foot is also a novelty that is using a $3 \mathrm{D}$ scanner.

\section{Methods}

Sixteen patients of RSUD (local public hospital) Tugurejo Semarang who suffer from calcanea spur participated in this study (Table 1). Calcanea spur location and dimension of each patient determined by lateral x-ray and assumed the base of the spur is located in the heel center line (Fig. 1a) [9]. Pain compressive points are specified in 7 locations, where the 7 th point is set at the base of spur and 6th point at the end of spur, another 5 points are made to be around the spur with the radius equal to spur length added with $1 \mathrm{~cm}$ (Fig. 1b). Pain minimum compressive pressure measured using algometer (FDIX 25, Wagner Instruments, Greenwich CT, USA) (Fig. 1c) [10].

Table 1. Subject characteristics

\begin{tabular}{|c|c|c|c|c|c|}
\hline $\begin{array}{c}\text { Gender } \\
\text { (male : female) }\end{array}$ & $\begin{array}{c}\text { Age } \\
\text { (years })\end{array}$ & $\begin{array}{c}\text { Body Weight } \\
(\mathrm{BW}, \mathrm{kg})\end{array}$ & $\begin{array}{c}\text { Body Height } \\
(\mathrm{BH}, \mathrm{cm})\end{array}$ & $\begin{array}{c}\text { Foot Length } \\
(\mathrm{FL}, \mathrm{mm})\end{array}$ & $\begin{array}{c}\text { Foot Width } \\
(\mathrm{FW}, \mathrm{mm})\end{array}$ \\
\hline $3: 13$ & $55 \pm 12$ & $61.9 \pm 9.5$ & $155 \pm 7$ & $251 \pm 14$ & $102 \pm 8$ \\
\hline
\end{tabular}

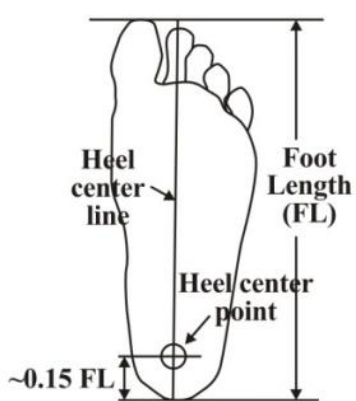

(a)

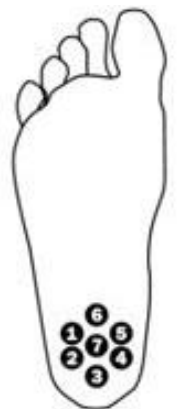

(b)

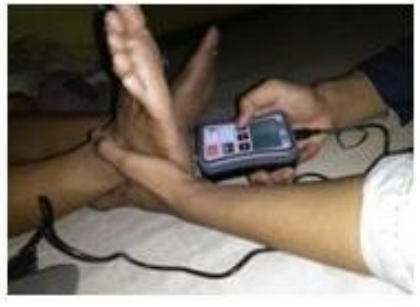

(c)

Fig 1. Point location of pain compressive test

The procedure of pain test are as follows: 1) press the skin at 7 points which have been set, 2) increasing pressure gradually and stop until patient's facial expression looks like level 6 or 7 [11],3) record value of the pressure that causes pain. From the record of quantitative data of pain, test results can be known : pain minimum compressive pressure and point location on each patient.

To obtain the load in heel area, a force measuring device had to be made using 3 FSR sensors (402, made by Interlink Electronics) [12] which attached at the heel area (of the total 8 sensors) these are at medial $(\mathrm{MH})$, lateral $(\mathrm{LH})$ and center of heel $(\mathrm{CH})$. Laying these sensors are determined based on the area of the foot that received the greatest load when the patient stands on the flat surface which is equivalent to the average of the biggest deformation obtained from the 3D scanner (Mini and Scansoft for Foot Orthotic made by Vismach Technology Ltd. China, red color image Fig. 2a) [13]. $\mathrm{CH}$ (sensor 7) is a point which is located in the heel center line at a distance 0.15 FL from the heel cup [14]. While LH (sensor 6) and MH (sensor 8) are measurement points in the lateral and medial heel areas that are determined arbitrarily but are still in the red image area (Fig. 2b) [15]. In this 
study, only the average pressure measurement results in $\mathrm{CH}$ compared with peak pressure obtained from FEM analysis because of its exact location. Every patient was asked to stand with barefoot above the shoe insole which has been installed with sensors, starting from heel height $0 \mathrm{~cm}$ (Fig. 2c). After the load in $\mathrm{CH}$ is recorded, the same procedure is performed for heel height 2 to $4 \mathrm{~cm}$.

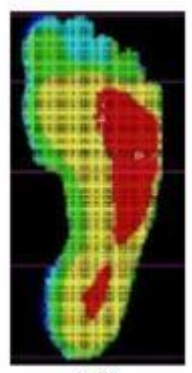

(a)

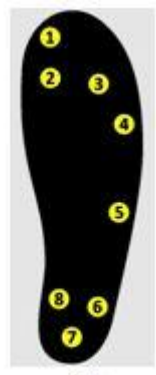

(b)

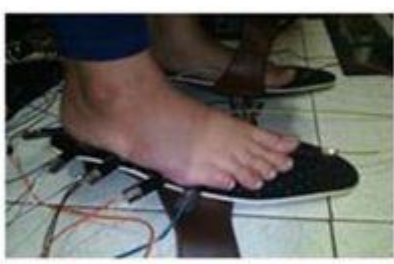

(c)

Fig. 2. The laying pattern of the FSR 402 sensor to measure the load on the foot due to its own weight

In this study the geometry of the patient plantar foot for building the FE model was obtained from a 3D scanner (Fig. 3a) $[13,16]$. The output can be in the form of the 3D positive model (Fig. 3b) and 3D foam positive impression (Fig. 3c). To obtain 3D solid model of foot, (.dxf) file from 3D scanner must be imported into Rhinoceros software in order to modify (or reduce) mesh and convert into ABAQUS file format (.jgs).

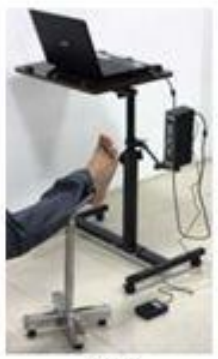

(a)

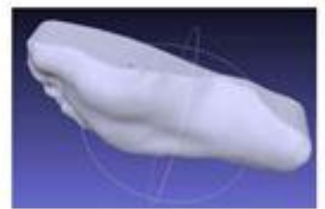

(b)

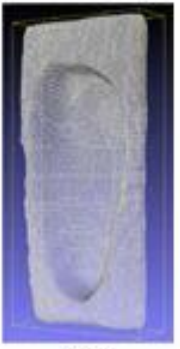

(c)

Fig. 3. The result of foot scanning from 3D scanner for foot orthotic

The measurement of sample some vertical distance along the craftsman-made shoes are used to estimate slope geometry function shoe insole 2 to $4 \mathrm{~cm}$ heel heights. This generated function used for FE modeling of the interaction between foot and insole (Fig. 4a) and make simple footwear of wood as a rigid body (Fig. 4b) for pressure measurement in the $\mathrm{CH}$ area of each patient.

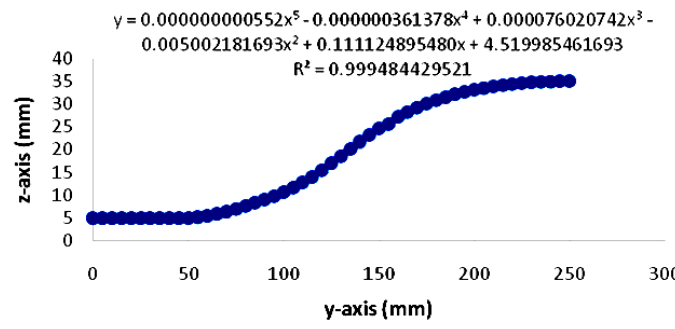

(a) generated function

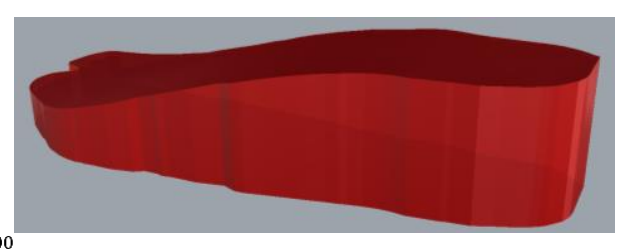

(b) modeling of footwear

Fig. 4. Polynomial function slope of shoe insole for heel height $3 \mathrm{~cm}$ 
To simulate the surface interaction between the foot (Fig. 3b) and the insole (Fig. 4b), ABAQUS automated surface-to-surface contact algorithm was used where the sole of the foot is defined as slave surface while shoe soles as the master surface. Because of the lubricating nature of the articulating surfaces, the contact behavior between the articulating surfaces can be considered frictionless. The next step is partly given material properties. The material used is human skin with Young's modulus $4.2 \times 10^{5} \mathrm{~N} / \mathrm{m}^{2}$ and Poisson's ratio $\mathrm{v}$ $=0.1$ [17] while shoe insole is assumed as a rigid body.

In order to simulate the movement of the foot following the contour of the shoe insole in the vertical direction while standing, the bottom of the shoe is restrained and the side of the sole of the foot given the boundary condition which can only move in the direction of the z-axis. Loading in the form of pressure applied on the upper surface of the foot of half the weight (in, $\mathrm{N}$ ) divided by the area of the upper foot (in, $\mathrm{m}^{2}$ ).

The procedure to find peak pressure in heel area (equivalent to the rear foot defined by Cavanagh [9]) for each heel height are as follows: 1) copy all coordinates data and pressures after FEM simulation into MS Excel software, 2) trace the peak pressure value in the heel area (z-value) and record its x-y coordinate. From the result can be known the difference of peak pressure value with pressure in $\mathrm{CH}$ and the peak pressure location distance to $\mathrm{CH}$ in heel area for every heel height of each patient (Fig.5).

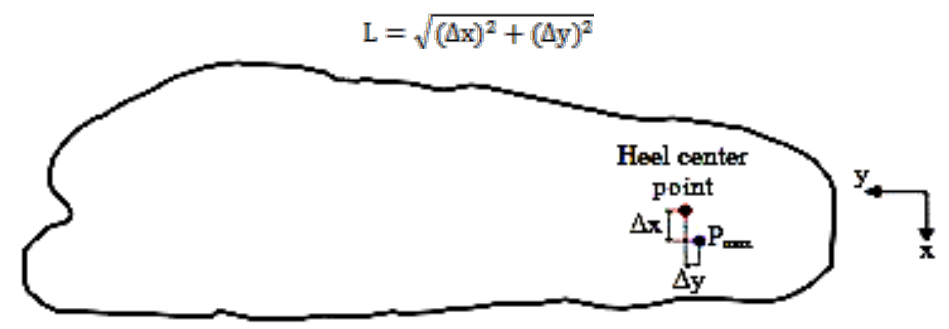

Fig. 5. The differentiation of peak pressure location to $\mathrm{CH}$

\section{Results}

The result of pain test of 16 patients found the average pain minimum compressive pressure is $183,057.29 \pm 78,980.88 \mathrm{~N} / \mathrm{m}^{2}$. The most location point of pain minimum compressive pressure are 11 at $1^{\text {st }}$ point $(48 \%)$ and 7 at $6^{\text {th }}$ point $(30 \%)$.

The average pressure in $\mathrm{CH}$ obtained by measurements is $142490.53 \mathrm{~N} / \mathrm{m}^{2}, 33010.04$ $\mathrm{N} / \mathrm{m}^{2}, 21764.39 \mathrm{~N} / \mathrm{m}^{2}$ and $21434.76 \mathrm{~N} / \mathrm{m}^{2}$ for heel height $0 \mathrm{~cm}, 2 \mathrm{~cm}, 3 \mathrm{~cm}$, and $4 \mathrm{~cm}$ respectively. Meanwhile average peak pressure obtained from FEM analysis are 170323.64 $\mathrm{N} / \mathrm{m}^{2}, 108259.03 \mathrm{~N} / \mathrm{m}^{2}, 99079.29 \mathrm{~N} / \mathrm{m}^{2}$, and $85232.55 \mathrm{~N} / \mathrm{m}^{2}$ at the location $9 \mathrm{~mm}, 8 \mathrm{~mm}, 8$ $\mathrm{mm}$, and $9 \mathrm{~mm}$ from $\mathrm{CH}$ for heel height $0 \mathrm{~cm}, 2 \mathrm{~cm}, 3 \mathrm{~cm}$, and $4 \mathrm{~cm}$ respectively.

As heel height increased, average peak pressure in heel region in the heel height $2 \mathrm{~cm}, 3$ $\mathrm{cm}$ and $4 \mathrm{~cm}$ are larger $3.86 \%$ and smaller $5.04 \%$ and $22.11 \%$ respectively compared to the smallest pain compressive pressure. The average peak pressure values are significantly higher than the average pressure in the $\mathrm{CH}$ measurement results amounted to $16.34 \%$, $69.51 \%, 78.03 \%$, and $74.85 \%$ for heel height $0 \mathrm{~cm}, 2 \mathrm{~cm}, 3 \mathrm{~cm}$ and $4 \mathrm{~cm}$ respectively. Except in heel height $0 \mathrm{~cm}$, all the average pressure from measurement results are lower than the smallest pain compressive pressure (Fig. 6a).

The difference in the average peak pressure and average pressure values is due to the location of average peak pressure by the FEM analysis result at about $8.5 \mathrm{~mm}$ to the $\mathrm{CH}$. The average pressure in $\mathrm{CH}$ obtained by FEM analysis are $162296.87 \mathrm{~N} / \mathrm{m}^{2}, 39211.50$ $\mathrm{N} / \mathrm{m}^{2}, 34636.37 \mathrm{~N} / \mathrm{m}^{2}$ and $28378.05 \mathrm{~N} / \mathrm{m}^{2}$ or differ at about $12.20 \%, 15.82 \%, 37.16 \%$ and 
$24.47 \%$ for heel height $0 \mathrm{~cm}, 2 \mathrm{~cm}, 3 \mathrm{~cm}$ and $4 \mathrm{~cm}$ respectively compared to the average pressure in $\mathrm{CH}$ obtained by measurements (Fig. 6b).

(a)

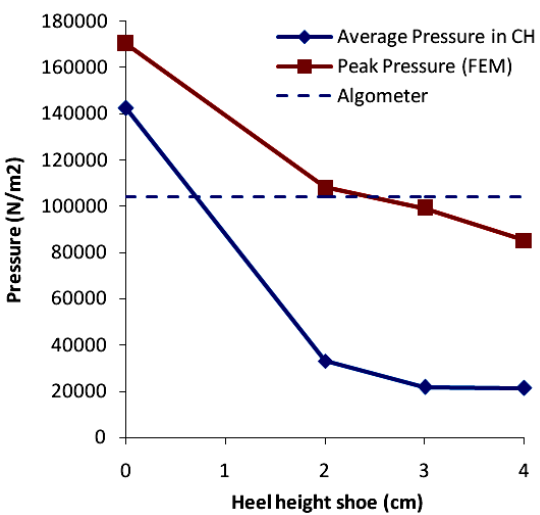

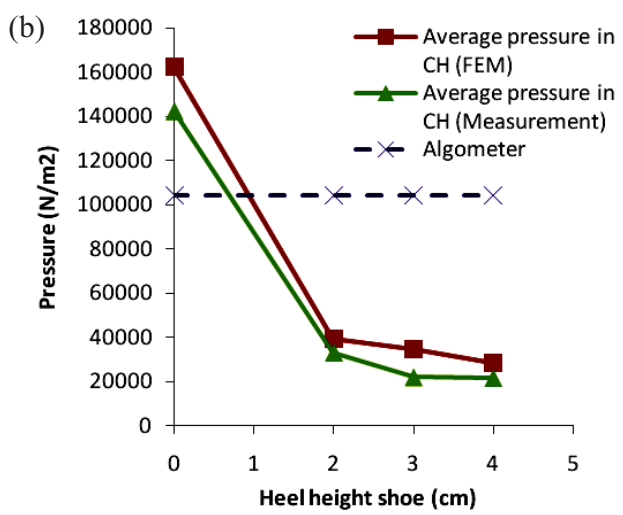

Fig. 6. The comparison of measurements and FEM analysis with pain minimum compressive pressure

\section{Discussion}

The results of pain compressive tests showed that the smallest pain compressive pressure occurs mostly at the point of the end of spur. This is consistent with the reality that suppression at the end of spur will result in the biggest bending moment at the base of the spur.

During standing as heel height increased, reduce pressure in heel region [3-6]. The significant difference average peak pressure obtained by the FEM analysis and average pressure obtained by the measurement result for all heel height shoe due to the location are not coincided.

Most of the location of patients peak pressure are in the medial heel area ( $\Delta \mathrm{x}$ value is positive, Fig. 5) which shows the position of the human foot tend to pronation while standing in an upright posture, but when shoe heel height is raising rearfoot pronation will reduce [3]. It is also seen from the measurement results that the average pressure in $\mathrm{MH}$ is greater than in LH. These results are in contrast to the research conducted by Pinto et al. which showed some signs of a supinated foot when standing in a balanced position [8]. Pinto researched only one obese patient feet whose body mass is $121 \mathrm{~kg}$. The differences in human foot position while standing may be caused by the position of the patient's pinto not completely straight when scanned.

The difference average pressure between the FEM analysis to measurement results caused by inaccuracy in load measurement. This is because the FSR 402 sensor is too thin (nominal thickness of $0.46 \mathrm{~mm}$ ) which does not really support the load perfectly in the $\mathrm{CH}$ area. Thus naturally pressure in $\mathrm{CH}$ from the measurement is lower than FEM analysis.

\section{Conclusion}

The differences of average pressure in $\mathrm{CH}$ between the FEM analysis to measurement results amounted $22.41 \%$ shows that laying of FSR sensors in $\mathrm{CH}$ is quite accurate. From this study for reasons of propriety and comfort of use, heel height $2 \mathrm{~cm}$ is suitable for male patients and $3 \mathrm{~cm}$ is for female patients. For heel height shoe, $2 \mathrm{~cm}$ is still a small pain because the value of the average pressure in $\mathrm{CH}$ is higher than $3.86 \%$ compared to the smallest pain compressive pressure. 
This work was supported by the Application and Development Research Grant UNDIP Contract No: SP DIPA - 042.01.2.400898/2016.

\section{References}

1) Jason KK Chia, Sanjay S., Angeline K., Jean LJ O., Jessie MT P. and Ai L. S. Comparative Trial of The Foot Pressure Patterns Between Corrective Orthotics, Formthotics, Bone Spur and Flat Insoles in Patients with Chronic Plantar Fasciitis. Ann Acad Med Singapore, 2009; 38: 869 - 75

2) Virginia L.G., Gary S.B., Robert T.W. and Dennis R. C. Calcaneal Loading During Walking and Running. Med. Sci. Sports Exerc., Vol. 32, No. 3, pp. 627-634, 2000

3) Mika S. and Paul D. A.. Effect of heel height on the foot in unilateral standing. J. Phys. Ther. Sci. 11: 95-100, 1999

4) Wei-Hsien Hong, Yung-Hui Lee, Hsieh-Ching Chen et al. Influence of heel height and shoe insert on comfort perception and biomechanical performance of young female adults during walking. Foot \& Ankle Int. Dec 2005 Vol. 26 no. 12 1042-1048

5) Yan Cong, Jason Tak-Man Cheung, Aaron KL Leung and Ming Zhang. Effect of heel height on in-shoe localized triaxial stresses. J. Biom 44 (2011) 2267-2272

6) Theresa Albon. Plantar force distribution for increasing heel height within women's shoes. Physics Department, The College of Wooster, Wooster, Ohio, December 2011

7) Jason Tak-Man Cheung and Ming Zhang. Finite element modeling of the human foot and footwear. 2006 ABAQUS Users' Conference

8) V. C.Pinto, N. V.Ramos, M. A. P.Vaz and M. A. Marques. 3D Modelling for FEM simulation of an obese foot. ResearchGate. Conf. Paper, January (2010)

9) Peter R. Cavanagh and Mary M. Rodgers. The Arch index: a useful measure from footprints. J. Biomechanics Vol. 20, No. 5, pp. 547-551, 1987

10) Wagner Instruments. Wagner FPTX Series Economy Manual Pain Threshold Testers. PAIN TEST ${ }^{\mathrm{TM}}$ ALGOMETER, USA

11) Holy Redeemer. Pain Level Chart. (https://lane.stanford.edu/portals/cvicu/HCP_Neuro_Tab_4/0-10_Pain_Scale.pdf)

12) Interlink Electronics. FSR Force Sensing Resistor - Integration Guide and Evaluation Parts Catalog. 400 Series Evaluation Parts with Suggested Electrical Interfaces, 546 Flynn Road, Camarillo, CA 93012

13) Dwi B.W., Gunawan D.H., and Agus P. Estimation of Foot Pressure from Human Footprint Depths Using 3D Scanner. AIP Conf. Proc., ISBN: 978-0-7354-1365-8, Vol. 1717, (2016). doi: 10.1063/1.4943451

14) Rodrigo, Asanka S., Goonetilleke, Ravindra S. and Xiong, Shuping, 2014. Load distribution to minimise pressure-related pain on foot: a model. Ergonomics, Vol. 56, no. $7,1180-1193$

15) Dwi B.W., Gunawan D.H., Achmad W., et al. Estimation of calcaneal loading during standing from human footprint depths using $3 D$ scanner. AIP Conf. Proc. 1788, 030063-1-030063-9 (2016); doi 10.1063/1.4968316

16) ScanPod3D, 2013. 3D Scanner Mini and Scansoft for Foot Orthotic. Vismach Technology Ltd., www.scanpod3d.com

17) P. G. Agache., C. Monneur., J. L. Leveque., J. De Rigal. Mechanical properties and young's modulus of human skin. Arch Dermatol Res 269, 221-232, 1980 